Ensino, Saúde e Ambiente - v. 14 n. esp. (2021): Dossiê Paulo Freire para além dos 100 anos:

construir utopias, transformar a realidade, p. 245-268.

Lutas Sociais e Educação Popular

ENSINO, SAÚDE E AMBIENTE

\title{
Paulo Freire, metodologias da educação popular e questões contemporâneas da relação ensino-aprendizagem
}

\section{Paulo Freire, methodologies of popular education and contemporary problems of the teaching-learning relation}

\author{
Rodrigo Lima Ribeiro Gomes ${ }^{1}$ \\ ${ }^{1}$ Doutor em Educação, IEAR/UFF, Angra dos Reis, Rio de Janeiro, Brasil - E-mail: rlrgomes@id.uff.br / ORCID: \\ https://orcid.org/0000-0001-6887-6349
}

Palavras-chave:

Paulo Freire; educação popular; ensino; aprendizagem; diálogo.

Keywords:

Paulo Freire; popular education; teaching; learning; dialogue.
RESUMO: O presente trabalho tem o objetivo de apresentar a contribuição de Paulo Freire para se pensar os problemas contemporâneos da relação ensino-aprendizagem, considerando as demandas das mudanças sociais. Procuramos situar as origens da pedagogia freiriana nos debates acerca da educação popular e de adultos de finais da década de 1950 até 1964, que culminaram no seu "método Paulo Freire de Educação de Adultos". Apresentamos alguns aspectos das ideias de Freire, desenvolvidos ao longo de sua trajetória, com o intuito de demonstrar como a forma de trabalhar de Freire, associada aos seus princípios político-pedagógicos, o levaram a abordar questões de grande atualidade. Para isso, recorremos brevemente a uma pequena amostra de artigos científicos escritos em inglês por pesquisadores de diversas partes do mundo, para demonstrar a relevância de Freire em nível internacional.

\begin{abstract}
This paper aims to present Paulo Freire's contribution to thinking about contemporary problems in the teaching-learning relationship, considering the demands of social changes. We seek to locate the origins of Freire's pedagogy in the debates about popular and adult education from the late 1950s to 1964, which culminated in his "Paulo Freire method of Adult Literacy". We present some aspects of Freire's ideas, developed along his trajectory, to demonstrate how Freire's way of working, associated with his political-pedagogical principles, led him to address issues of great relevance. For this, we briefly resorted to a small sample of scientific articles written in English by researchers from different parts of the world, to demonstrate Freire's relevance at an international level.
\end{abstract}

\section{INTRODUÇÃO}

O legado de Paulo Freire tem sido fortemente questionado em nosso país nos últimos anos, em razão do avanço conservador que se tem observado no Brasil (CHABALGOITY, 2020). Contudo, o educador pernambucano segue sendo uma referência importante em diversas áreas de pesquisa das Humanidades - em especial, a Educação - pelo mundo, o que pode ser atestado por uma breve busca pela palavra-chave "Paulo Freire" no Portal de Periódicos da CAPES, restringindo a busca à língua inglesa - utilizada como língua 
Ensino, Saúde e Ambiente - v. 14 n. esp. (2021): Dossiê Paulo Freire para além dos 100 anos: construir utopias, transformar a realidade, p. 245-268.

\section{Lutas Sociais e Educação Popular}

acadêmica por periódicos especializados de diversos países. O sistema encontrou 7.424 artigos científicos revisados por pares, em 06 de abril de 2021. ${ }^{1}$

Não se trata de dizer que todo esse material reflete pesquisas orientadas por um referencial teórico-metodológico "freiriano", o que não seria acurado. Mas se deve salientar que Paulo Freire segue influenciando reflexões a respeito de vários temas contemporâneos articulados à Educação, como relações de gênero, trabalho pedagógico com imigrantes, relações étnico-raciais, decolonialidade e educação ambiental, para nos restringir a alguns dos mais relevantes.

Por certo, um mapeamento acerca do conjunto de problemáticas que evocam Paulo Freire seria impraticável. Assim sendo, tendo em mente que o autor aqui em tela teve sua trajetória essencialmente vinculada à Educação, nosso recorte neste trabalho tem como foco a relação ensino-aprendizagem, questão para a qual Freire ofertou contribuições inequívocas. Nossa hipótese é de que a grande quantidade de citações e referências a Paulo Freire ao redor do mundo relaciona-se ao fato de o educador apresentar uma espécie de síntese das principais questões pedagógicas contemporâneas em sua trajetória.

Por certo, trazer Paulo Freire ao centro do debate, no Brasil de hoje, tem como problema subjacente a seguinte questão política posta por Kohan (2019, p. 22): “Como é possível que, mundo afora, as edições de seus livros sejam lidas por milhões e aqui se pretenda expurgá-lo da educação brasileira?”. Além dessa reflexão, Kohan (2019, p. 24) põe outra pergunta, também relacionada ao amplo impacto de Freire, mas de cunho metodológico: "diante de tantas obras sobre o autor pernambucano, como não repetir o já escrito, como não abusar do já pensado e como recriar seu pensamento em nossa atualidade sem reproduzir o já produzido?’.

A segunda questão de Kohan acima diz respeito às dificuldades de se realizar reflexões originais a partir do pensamento de Paulo Freire, considerando que se trata de um autor muito lido e citado, sob uma infinidade de perspectivas. Uma resposta convincente àquela pergunta suporia uma quantidade de leituras provavelmente impossível de ser realizada por um indivíduo isolado. Contudo, esse não deve ser um problema que bloqueie iniciativas de novas leituras e interpretações acerca do pensamento e da ação de um autor tão relevante.

Ressalvado o problema de Kohan, nosso objetivo neste trabalho é o seguinte: a partir de uma reflexão histórica que articula a práxis freiriana aos debates metodológicos realizados no âmbito da temática da educação popular, sinalizar para a atualidade da pedagogia de Paulo

\footnotetext{
${ }^{1}$ De acordo com Walter Kohan (2019, p. 16): "Uma pesquisa recente feita no Google Scholar, realizada por Elliot Green, mostra que A pedagogia do oprimido é, no mundo inteiro, a terceira obra mais citada no campo das ciências sociais. Os números e o dado impressionam: 72 mil vezes citado, o livro é o primeiro do mundo na área de educação".
} 
Ensino, Saúde e Ambiente - v. 14 n. esp. (2021): Dossiê Paulo Freire para além dos 100 anos: construir utopias, transformar a realidade, p. 245-268.

\section{Lutas Sociais e Educação Popular}

Freire no que concerne às propostas contemporâneas acerca da relação ensino-aprendizagem. Com isso, assinalamos implicitamente o equívoco das propostas antifreirianas, que visam retomar práticas de ensino tradicionalistas, há muito superadas, que tenderão a desconectar a educação brasileira das práticas pedagógicas de ponta em nível mundial.

Com a afirmação acima, não afirmamos que toda crítica a Paulo Freire seja equivocada ou que a pedagogia freiriana seja uma panaceia. Nosso argumento central é que as propostas anti Paulo Freire são retrógradas, tendem a apontar para relações ensinoaprendizagem hierarquizadas, autoritárias, não condizentes com as necessidades educacionais contemporâneas.

Procuraremos demonstrar nosso argumento recorrendo - ao modo de um ensaio bibliográfico, de modo breve - a dez artigos científicos publicados em inglês, em revistas internacionais de relevância reconhecida, revisadas por pares, e publicadas nos últimos dez anos - parâmetros utilizados no portal de periódicos da CAPES. Inserimos o termo de busca "Paulo Freire", selecionando o tema "Teaching Methods", o que nos levou a localizar 517 artigos. Na nossa seleção, levamos em consideração as diversidades geográfica e temática, além da relevância dos artigos levantados.

Nosso intuito não é fazer uma análise exaustiva desses textos internacionais. Nossa estratégia argumentativa consiste na apresentação do contexto em que a pedagogia freiriana foi desenvolvida em suas origens, realizando um brevíssimo histórico do debate ao redor dos sentidos e práticas em educação popular e educação de adultos para o auxílio à compreensão das bases do chamado "Método Paulo Freire de Alfabetização de Adultos". Em seguida, apresentamos, de modo sumário, alguns elementos da concepção pedagógica de Freire que julgamos centrais para a compreensão de sua práxis, articulados a uma breve exposição de sua trajetória, tentando demonstrar a relevância de suas reflexões para os problemas contemporâneos no que concerne à relação ensino-aprendizagem. Por fim, abordamos alguns dos usos de Freire pelo mundo, a partir dos artigos mencionados no parágrafo anterior e concluímos refletindo sobre a pertinência pedagógica do educador pernambucano e sobre a inadequação de propostas que se afirmem como anti Paulo Freire.

\section{OS DEBATES METODOLÓGICOS EM EDUCAÇÃO POPULAR E ALFABETIZAÇÃO DE ADULTOS: ORIGENS DA PEDAGOGIA FREIRIANA}

Um dos questionamentos que se faz a Paulo Freire refere-se à falta de originalidade de seu método de alfabetização de adultos, supostamente, no argumento de alguns críticos, uma 
Ensino, Saúde e Ambiente - v. 14 n. esp. (2021): Dossiê Paulo Freire para além dos 100 anos: construir utopias, transformar a realidade, p. 245-268.

\section{Lutas Sociais e Educação Popular}

“imitação" do método de alfabetização de Laubach (GOMES, 2017). ${ }^{2}$ A questão que interessa a nosso objetivo aqui, porém, não é a técnica de alfabetização em si, mas os princípios pedagógicos que fundamentam o Método Paulo Freire de Alfabetização de Adultos.

De início, é importante salientar duas coisas: 1) a proposta freiriana é uma espécie de síntese de uma longa discussão que vinha ocorrendo, no Brasil, a respeito da pertinência e das metodologias da educação de adultos; e 2) os sentidos do termo "educação popular" variaram ao longo da história brasileira, e passaram a ser atravessados pelos debates em torno da educação de adultos sobretudo a partir das décadas de 1930 e 1940 (GOMES, 2020).

Pode-se afirmar que a educação de adultos se torna um problema de grande relevância depois da Revolução de 30 por duas razões básicas. Em primeiro lugar, o governo Vargas (1930-45) pôs em prática um processo de centralização administrativa que colocou, de modo mais efetivo, a política educacional como uma política nacional, tomando iniciativas institucionais nesse sentido. Em segundo lugar, Vargas adotou uma política de favorecimento ao desenvolvimento industrial, o que demandava a formação de uma força de trabalho dotada de habilidades adequadas ao labor fabril moderno (RODRIGUES, 1998).

Com isso, ampliam-se os debates a respeito da metodologia da educação popular de adultos - entendendo que, no contexto das décadas de 1930 e 1940, “educação popular" era compreendida com o sentido de uma educação para o povo, uma "educação comum para todos os cidadãos", de iniciativa do Estado, que remontava à década de 1820 (BEISIEGEL, 2004, p. 71-79), relacionada à estruturação do Brasil como país independente, e com a influência universalista advinda da Revolução Francesa.

Já desde o final da década de 1930, pelo menos, pensadores da educação tinham a noção de que a metodologia da educação de adultos não poderia ser a mesma das crianças e adolescentes que passaram pela escolarização na idade considerada adequada, como se pode atestar a partir do livro Educação supletiva. Educação de adultos, de Paschoal Lemme (2004), publicado originalmente em 1940. Nesta obra, esse "pioneiro da Educação Nova" baseia-se nas pesquisas internacionais realizadas no âmbito da educação de adultos, especialmente a contribuição do que chama de "psicologia da aprendizagem", para defender uma relação ensino-aprendizagem específica para os adultos.

A perspectiva de uma pedagogia distinta na educação de adultos aparece como fundamento da principal iniciativa de educação massiva de adultos da década de 1940, a Campanha de Educação de Adolescentes e Adultos (CEAA). Em 1945, Lourenço Filho, outro

${ }^{2}$ Crítica com a qual não concordamos, como o exposto em Gomes (2017). 
Ensino, Saúde e Ambiente - v. 14 n. esp. (2021): Dossiê Paulo Freire para além dos 100 anos: construir utopias, transformar a realidade, p. 245-268.

\section{Lutas Sociais e Educação Popular}

"pioneiro da Educação Nova" e Diretor-Geral da Campanha, utilizando-se da mesma referência de Pachoal Lemme, o psicólogo da aprendizagem Edward L. Thorndike, defende que a educação de adultos precisa ser praticada com uma metodologia específica, diferenciando-se da metodologia usada com as crianças: dever-se-ia evitar o uso de cartilhas infantis, produzindo novos materiais adequados "ao vocabulário e aos interesses do aluno". Ademais, as cartilhas infantis poderiam também contribuir para aumentar o "sentimento de inferioridade" dos adultos educandos. Por isso, a educação de adultos deveria "tratar de assuntos de interesse direto da vida do aluno", com lições orais que deveriam ter, preferencialmente, a "forma do diálogo". Para aquele educador, se o adulto percebesse que o ensino não the era "funcional", ele perderia o interesse por "senti-lo menos útil ou pouco oportuno" (LOURENÇO FILHO [1945], 2000, p. 124).

Ou seja, dois aspectos essenciais da pedagogia freiriana já faziam parte das discussões em torno da metodologia da educação popular de adultos desde os anos de 1940, pelo menos. Contudo, por óbvio, nem os problemas metodológicos da educação de adultos, nem o próprio método de alfabetização de Paulo Freire, podem ser reduzidos apenas ao trabalho pedagógico a partir dos interesses dos educandos, utilizando a "forma do diálogo". O conceito que orientou as campanhas massivas de educação de adultos das décadas de 1940 e 1950, como a própria CEAA, foi o de "educação fundamental", a partir de uma proposta da UNESCO visando o impulso ao desenvolvimento socioeconômico dos países do chamado "Terceiro Mundo", através de ações educativas, que combinavam noções básicas de língua e matemática com o ensino técnico adaptado às realidades locais. Tratava-se, no entendimento da UNESCO, de promover "os conhecimentos e as atitudes mentais fundamentais para qualquer comunidade insuficientemente desenvolvida que tenha que conservar seus próprios valores e aprender a lidar com seus próprios assuntos durante um período de rápida expansão econômica" (UNESCO, 1949, p. 235).

É importante salientar que, nas duas décadas que antecederam ao surgimento do método de alfabetização de Paulo Freire, o debate acerca da educação popular de adultos esteve muito articulado ao discurso do desenvolvimento econômico, com ênfase na industrialização, o que influenciou o próprio educador pernambucano. Ao mesmo tempo, de modo paradoxal, defendia-se a preservação das características culturais locais, o que se conecta à ideia de realização do trabalho pedagógico a partir das referências dos próprios educandos - presente também na pedagogia freiriana. E, de acordo com Beisiegel, “os apelos internacionais no sentido da articulação de campanhas de educação de adultos analfabetos e o 
Ensino, Saúde e Ambiente - v. 14 n. esp. (2021): Dossiê Paulo Freire para além dos 100 anos: construir utopias, transformar a realidade, p. 245-268.

\section{Lutas Sociais e Educação Popular}

quadro conceitual elaborado no âmbito da UNESCO seriam fácil e rapidamente absorvidos no Brasil” (BEISIEGEL, 2004, p. 79).

Como já vimos, essa influência da concepção de "educação fundamental” da UNESCO orientou as campanhas massivas de educação de adultos, como a já mencionada CEAA (19471963), além da Campanha Nacional de Educação Rural (CNER), iniciada em 1952. Essas iniciativas, somadas à expansão da rede escolar pelo país, tiveram significativo impacto na educação nacional, reduzindo, por exemplo, a taxa de analfabetismo da população brasileira maior de 15 anos de idade, de 56,1\%, em 1940, para 39,7\%, em 1960, conforme dados do censo realizado pelo IBGE, num período em que a ampliação demográfica dessa faixa da população saltou da ordem de 23 milhões para 40 milhões de pessoas (BRASIL, 2003, p. 6).

Contudo, no final da década de 1950, essas campanhas começam a ser alvo de críticas, tanto do ponto de vista político quanto do ponto de vista pedagógico. A CEAA foi muito criticada durante o II Congresso Nacional de Educação de Adultos, realizado em 1958, no Rio de Janeiro, com denúncias sobre sua desorganização administrativa, exiguidade de recursos e falta de professores qualificados para levar a cabo um trabalho de ensino minimamente qualificado. Além disso, a Campanha era acusada de ter um cunho basicamente político: ao conferir apenas uma alfabetização mínima para os alunos, ela teria como objetivo velado a ampliação do contingente eleitoral do país, ou seja, não passaria de uma "fábrica de eleitores" (PAIVA, 2003, p. 220). ${ }^{3}$ Naquele Congresso, criticou-se também a "ausência de formação específica para o professorado, assim como a falta de métodos e conteúdos pensados particularmente para a educação de adultos" (SOARES, 2008, p. 84).

É precisamente nesse contexto que surge a primeira contribuição notória de Paulo Freire no debate educacional, no âmbito do Relatório final do Seminário Regional de Educação de Adultos, a contribuição dos pernambucanos ao II Congresso Nacional de Educação de Adultos, de 1958, acima mencionado. Paulo Freire foi o relator da terceira comissão, cujo tema era "A educação de adultos e as populações marginais: o problema dos mocambos" (FREIRE et al [1958], 2013, p. 151-153). De certa forma - embora reverberando as críticas à situação educacional do país, entendida como um "transplante" de iniciativas estrangeiras à condição nacional, sendo, portanto, "inautêntica" e resultante de uma mentalidade ainda "colonial" -, Paulo Freire apresenta muitas das características contidas no conceito de "educação fundamental" da UNESCO. Pensa o desenvolvimento industrial como

\footnotetext{
${ }^{3}$ A ampliação do eleitorado ocorreria porque a Constituição brasileira de 1946 vedava o direito ao voto às pessoas analfabetas. Ampliar o contingente de alfabetizados significava, portanto, aumentar o número de votantes.
} 
Ensino, Saúde e Ambiente - v. 14 n. esp. (2021): Dossiê Paulo Freire para além dos 100 anos: construir utopias, transformar a realidade, p. 245-268.

\section{Lutas Sociais e Educação Popular}

condição de superação da pobreza, mas demonstra preocupações com as possibilidades de excessiva modificação das características culturais das classes populares, o que deveria ser combatido com uma educação que, pela forma do diálogo, procurasse despertar uma consciência crítica nos educandos, com o intuito de inseri-los criticamente numa vida moderna e democrática, mas mantendo características culturais regionais e nacionais próprias.

Nesse contexto, fins da década de 1950, tem início uma série de movimentos de renovação da educação de adultos e da educação popular, dentre os quais Paulo Freire ajudou a fundar e foi um eminente integrante de um, talvez o mais influente: o Movimento de Cultura Popular (MCP), surgido no Recife, em 1960, como uma iniciativa do prefeito Miguel Arraes, em conjunto com intelectuais, educadores e artistas, posteriormente ampliado para o âmbito estadual, quando Arraes se elegeu para governador de Pernambuco, em 1962.

O MCP tinha um amplo espectro de atuações: organizava escolas, manifestações culturais e artísticas diversas, agindo até na área da saúde pública, mobilizando setores da sociedade para atuar em problemas sociais como braços do Executivo (COELHO, 2012). Paulo Freire se somou ao movimento precisamente no setor de alfabetização de adultos, área responsável pela elaboração do, à época, célebre Livro de leitura para adultos, que inovava pela técnica de alfabetização ativa ("palavração") e por um conteúdo que intentava buscar uma identificação com os educandos (MCP [1962], 1986). De acordo com o Diretor do movimento, Germano Coelho, Paulo Freire teria se entusiasmado pelo livro, mas decidiu elaborar um método de alfabetização próprio, que prescindiria do uso de cartilha. Tal seria a origem do conhecido método de alfabetização de adultos de Paulo Freire (COELHO, 2002, p. 58-59).

O chamado "método" ou "sistema" de alfabetização de adultos de Freire foi experimentado, então, em 1962, no "centro de cultura" Dona Olegarinha, no âmbito do MCP (ARY, 1962), e teve sua primeira aplicação, como política pública, em 1963, no município potiguar de Angicos, como iniciativa do governo estadual do Rio Grande do Norte, de Aluísio Alves. Seus bons resultados obtidos em um curto período, que totalizava quarenta horas, alçaram o educador à celebridade nacional e internacional (FERNANDES; TERRA, 1994; LYRA, 1996).

O método de alfabetização de adultos de Freire é bem conhecido: inicialmente, realizava-se uma pesquisa na comunidade onde ocorreria o processo pedagógico, com o intuito de produzir um levantamento do "universo vocabular" do educandos, um conjunto de palavras (entre quinze e trinta, aproximadamente) que expressassem diversidade fonética e fossem significativas à experiência do educando; organizavam-se os "círculos de cultura", nos quais educadores e educandos dialogavam acerca das condições de vida dos alfabetizandos; 
Ensino, Saúde e Ambiente - v. 14 n. esp. (2021): Dossiê Paulo Freire para além dos 100 anos: construir utopias, transformar a realidade, p. 245-268.

\section{Lutas Sociais e Educação Popular}

começava-se o processo com a apresentação do que Freire chamava de "conceito antropológico de cultura", buscando trabalhar com os educandos a ideia de que eles eram seres dotados de cultura, distintamente aos demais animais, que as diferentes culturas eram diversas e legítimas, e que, portanto, as tradições dos educandos não seriam "inferiores" a nenhuma outra - além de procurar convencer os educandos de que, com sua própria cultura, já realizavam uma "leitura" do mundo; ao longo do processo de alfabetização especificamente, as palavras já eram apresentadas como tais, juntamente com imagens que as representavam; dialogava-se acerca de temas suscitados pelas imagens, e, na sequência, as palavras eram apresentadas sem a imagem, decompostas em sílabas, sendo, por fim, divididas conforme suas famílias silábicas. Desde o início, os educandos eram incentivados a formar palavras a partir das sílabas decompostas - ainda que fossem palavras inexistentes, ou com erros de escrita -, com grau crescente de complexidade fonética. Por fim, depois de quarenta encontros de uma hora cada, avaliava-se não apenas a capacidade de leitura e escrita (obviamente, ainda iniciantes), mas também o que Freire chamava de "politização", ou seja, a capacidade de o educando articular a habilidade adquirida com o letramento a uma visão de mundo mais profunda acerca de suas próprias condições de vida (FREIRE, 1983; FREIRE, 1992).

\section{PAULO FREIRE ALÉM DO MÉTODO DE ALFABETIZAÇÃO: UM FILÓSOFO DA PRÁXIS PEDAGÓGICA}

Como já salientamos anteriormente, nosso objetivo não é nos deter no método de alfabetização, mas apontar como os fundamentos político-pedagógicos do "método Paulo Freire" marcaram sua práxis educativa ao longo de sua trajetória e guardam grande pertinência diante dos dilemas contemporâneos da relação ensino-aprendizagem.

A primeira obra de destaque de Paulo Freire, depois da experiência brasileira sintetizada em Educação como prática da liberdade, de 1967, foi, sem dúvida, Pedagogia do oprimido, livro escrito em 1968, e publicado, pela primeira vez, em 1970, nos EUA e no Brasil. ${ }^{4}$ É a obra mas citada pelos autores de diversos países levantados para este texto, constituindo-se como a principal referência do pensamento freiriano em nível internacional.

Entre Educação como prática da liberdade, que é uma publicação revista e ampliada da tese Educação e atualidade brasileira, de 1959, com exposições acerca de sua experiência com o método de alfabetização em Angicos, e Pedagogia do oprimido, observa-se um

\footnotetext{
${ }^{4}$ Freire publicou outras obras em diversas línguas entre 1967 e 1970, mas Pedagogia do oprimido foi a mais impactante, como se pode constatar em Gadotti et al (1996, p. 257-264).
} 
Ensino, Saúde e Ambiente - v. 14 n. esp. (2021): Dossiê Paulo Freire para além dos 100 anos: construir utopias, transformar a realidade, p. 245-268.

\section{Lutas Sociais e Educação Popular}

movimento no pensamento de Freire, representativo de um período produtivo de trabalho intenso do educador exilado no Chile (FREIRE, 2013, p. 175-178). Referências a marxistas e pensadores anticoloniais revolucionários como Che Guevara, Franz Fanon e Mao Zedong figuram ao lado de autores frequentes nas obras anteriores, como Álvaro Vieira Pinto e Karl Jaspers (FREIRE, 2005).

Antes de representar uma "radicalização" política de Paulo Freire, ainda que também o seja, ${ }^{5}$ no plano teórico, Pedagogia do oprimido representa a articulação e o avanço de três movimentos que se conectam com as ideias e as propostas do educador no período do desenvolvimento de seu método de alfabetização, que podem ser compreendidas sinteticamente como partes de uma concepção pedagógica anticolonial. Os três movimentos seriam: o aspecto anticolonial no sentido de emancipação nacional, que Freire refletia a partir da influência de Vieira Pinto e de outros autores do Instituto Superior de Estudos Brasileiros (ISEB), ${ }^{6}$ sua expansão no sentido de uma emancipação latino-americana - depois também africana, a partir do trabalho do educador em países recém independentes do continente, ao longo da década de 1970 - e uma “descolonização das consciências”, expressa já nas influências do personalismo cristão, nas críticas à massificação e no conceito de "conscientização".

A "teoria da ação dialógica", que Freire (2005, p. 191-213) apresenta no final da Pedagogia do oprimido, é, ao mesmo tempo, uma herdeira das discussões metodológicas acerca da especificidade da educação de adultos, que entende que a "forma do diálogo" é a mais eficiente para a obtenção de resultados com esse público de educandos, e a principal novidade introduzida pelo educador no debate pedagógico. Afirmamos isso porque, em Freire, é possível detectar a preocupação que aqui chamamos de anticolonial desde o Relatório da equipe pernambucana que Freire coordenou, como contribuição ao II Congresso Nacional de Educação de Adultos, de 1958 - mencionado anteriormente.

Em Freire, a "forma do diálogo" nunca foi apenas uma técnica de ensino, mas também um método para estabelecer uma relação ensino-aprendizagem capaz de provocar nos educandos a capacidade de desenvolvimento de um pensar autônomo, crítico, promotor de uma capacidade de iniciativa individual a partir da habilidade de trabalhar em grupos, de compreender criticamente a realidade e de agir para a sua transformação - sempre em sentido emancipatório. Além disso, a ideia de partir da realidade dos educandos e produzir materiais

\footnotetext{
${ }^{5}$ Vale lembrar que Pedagogia do oprimido foi escrito no contexto das sublevações de jovens ao redor do mundo, no ano de 1968, as quais Paulo Freire (2005, p. 31) menciona na primeira nota do capítulo 1.

${ }^{6}$ Instituto que Freire visitou no começo da década de 1960, mantendo relações com alguns de seus intelectuais.
} 
Ensino, Saúde e Ambiente - v. 14 n. esp. (2021): Dossiê Paulo Freire para além dos 100 anos: construir utopias, transformar a realidade, p. 245-268.

\section{Lutas Sociais e Educação Popular}

pedagógicos baseados em pesquisas sobre suas experiências e palavras mais significativas tampouco não se refere apenas a uma técnica de ensino, mas busca superar uma educação massificadora que homogeneíze os indivíduos e lhes imponha de fora outra cultura, de modo "colonizante".

Por isso, sua crítica ao caráter "bancário" das pedagogias convencionais (FREIRE, 2005, p. 65-87). A começar pela crítica política de utilizar os bancos como metáfora para definir a pedagogia convencional. Mas, além disso, a metáfora bancária sustenta a noção de que as pedagogias convencionais tratam os educandos como "tábulas rasas", desprovidos de culturas, saberes e valores próprios, devendo, portanto, ser objeto de "depósito" de conhecimentos que lhes são estranhos, externos, impostos. Em certo sentido, se pode dizer que a "educação bancária" é também colonizante.

A orientação anticolonial, em sentido amplo, nos parece ser o núcleo do que podemos chamar de pedagogia freiriana. Não à toa, Paulo Freire é um dos autores de referência também de algumas teorias da decolonialidade (PENNA, 2014), muito embora, não creiamos que Freire compartilhe da crítica de algumas teorias decoloniais à modernidade tout court. Basta lembrarmos que o educador considerava a industrialização um "imperativo existencial” para o Brasil, calcado na noção de Vieira Pinto (e do ISEB, de modo geral) de que o país seria uma "semicolônia". A modernização seria constitutiva do processo de emancipação nacional. Contudo, caberia à educação dialógica e emancipadora combater as tendências alienantes e massificantes também contidas nas sociedades de massas modernas, preservando valores locais, regionais e nacionais, contribuindo para uma integração consciente das pessoas.

O projeto político-pedagógico de Freire insere-se numa complexa dialética entre autonomia individual, emancipação nacional e conservação de tradições culturais - ao menos conservação de seus aspectos não repressivos e autoritários. Percebemos essas articulações em seus escritos da década de 1970, refletindo sua atuação em países africanos que estavam enfrentando ou tinham acabado de enfrentar lutas de libertação anticolonial.

$\mathrm{Na}$ "Introdução" às suas Cartas à Guiné-Bissau, escritas em 1975 e 1976, por exemplo, Freire explicita a questão da educação de adultos, em especial a alfabetização e pósalfabetização, no contexto de uma nação recentemente libertada do jugo colonial português que, apesar de apresentar elevado grau de consciência política, lutava contra a precariedade econômica herdada da situação colonial, associada a elevados índices de analfabetismo - ao redor de $90 \%$ da população, segundo o educador. As questões postas por ele, apesar de refletirem esse contexto, são uma boa síntese de sua concepção, que se expressava desde o 
Ensino, Saúde e Ambiente - v. 14 n. esp. (2021): Dossiê Paulo Freire para além dos 100 anos: construir utopias, transformar a realidade, p. 245-268.

\section{Lutas Sociais e Educação Popular}

final da década de 1950 e persistirá por toda a sua trajetória. Em suas experiências, segundo ele, jamais teria se detido

[...] no estudo de métodos e de técnicas de alfabetização de adultos em si mesmos, mas no estudo deles e delas enquanto a serviço de, e em coerência com uma certa teoria do conhecimento posta em prática, a qual, por sua vez, deve ser fiel a uma certa opção política. Neste sentido, se a opção do educador é revolucionária e se sua prática é coerente com sua opção, a alfabetização de adultos, como ato de conhecimento, tem, no alfabetizando, um dos sujeitos deste ato. Desta forma, o que se coloca a tal educador é a procura dos melhores caminhos, das melhores ajudas que possibilitem ao alfabetizando exercer o papel de sujeito de conhecimento no processo de sua alfabetização. O educador deve ser um inventor e um re-inventor constante desses meios e desses caminhos com os quais facilite mais e mais a problematização do objeto a ser desvelado e finalmente apreendido pelos educandos. Sua tarefa não é a de servir-se desses meios e desses caminhos para desnudar, ele mesmo, o objeto e depois entregá-lo, paternalisticamente, aos educandos, a quem negasse o esforço da busca, indispensável ao ato de conhecer (FREIRE, 2011a, p. 20-21).

$\mathrm{Ou}$ seja, mais importante do que a técnica, é o fundamento que a precede, que mobiliza ferramentas em conformidade aos seus objetivos político-pedagógicos. Além disso, na relação de ensino-aprendizagem, mais fundamental do que o conhecimento a ser trabalhado é a relação que educadores e educandos estabelecem entre si, e deles para com o saber, na qual o docente atua com o intuito de auxiliar o discente a refletir autonomamente acerca dos problemas:

$\mathrm{Na}$ verdade, nas relações entre o educador e os educandos, mediatizados pelo objeto a ser desvelado, o importante é o exercício da atitude crítica em face do objeto e não o discurso do educador em torno do objeto. E mesmo quando, nestas relações, em que educador e educandos, curiosos, se acercam ao objeto de sua análise, os segundos necessitam de alguma informação, indispensável ao prosseguimento da análise, pois que conhecer não é adivinhar, a informação deve ser precedida de certa problematização. Sem esta, a informação deixa de ser um momento fundamental do ato de conhecimento para ser a transferência que dele faz o educador aos educandos (FREIRE, 2011a, p. 21). ${ }^{7}$

Tais aspectos da pedagogia freireana são centrais não apenas para a compreensão da práxis do educador pernambucano, como também constituem alguns dos principais problemas

\footnotetext{
${ }^{7}$ Nesse ponto, Freire volta a assinalar sua recusa a cartilhas, precisamente porque, segundo o educador, nelas o autor ou a autora do material pedagógico realizam "grande parte do esforço a ser realizado pelos alfabetizandos, sobretudo no momento de criação de suas palavras (FREIRE, 2011a, p. 22).
} 
Ensino, Saúde e Ambiente - v. 14 n. esp. (2021): Dossiê Paulo Freire para além dos 100 anos: construir utopias, transformar a realidade, p. 245-268.

\section{Lutas Sociais e Educação Popular}

relativos à relação ensino-aprendizagem contemporaneamente, como veremos. As experiências de Paulo Freire em países africanos consolidaram e expandiram essas perspectivas do educador tanto em relação à prática pedagógica quanto a novas formas de escrita e publicação de livros. É nesse contexto que surgem os livros "dialogados" que marcaram a produção freireana da década de 1980, surgidos de conversas com educadores parceiros como Sérgio Guimarães, Antonio Faundez, Ira Shor e outros. ${ }^{8}$

Uma característica marcante desses textos "dialogados" é a representação de uma forma de elaboração teórica muito particular, que se desenvolve dialogicamente, rememorando e refletindo acerca de experiências pedagógicas concretas e muito significativas, nos diversos países e contextos em que atuou. Como observa Tagliavia (2008, p. 27), "o partir da experiência e da práxis pedagógica para alcançar, apenas em uma segunda etapa, a elaboração teórico-filosófica educativa, representa uma atitude constante em toda a obra do pedagogo brasileiro".

Esse "teorizar" a partir de projetos pedagógicos já encerrados não era realizado sem fundamentos, uma vez que o autor partia de princípios muito claros, que aqui classificamos como anticoloniais. As reflexões de Freire não buscavam nenhuma sistematicidade e estavam abertas a refletir acerca de seus limites, como as conhecidas dificuldades que o educador e sua equipe enfrentaram, nos países africanos recém libertos do jugo colonial português, como Guiné-Bissau, Santo Tomé e Príncipe e Angola, para alfabetizar adultos na língua portuguesa. Nessas situações, a língua portuguesa seria mais um instrumento de dominação do que de constituição das culturas nacionais desses países, ficando restrita a pequenos grupos da elite intelectual e dirigente, enquanto os povos conservavam suas línguas próprias. Porém, do ponto de vista da alfabetização daquelas populações, isso também punha problemas, uma vez que essas línguas não possuíam sistemas de escrita (FREIRE, 2011b).

De acordo com Moacir Gadotti, na sua apresentação à Por uma pedagogia da pergunta, a experiência africana levou Paulo Freire à realização e incorporação de novas reflexões, sobretudo acerca da relação entre as possiblidades e limites do trabalho pedagógico e as condições socioeconômicas do contexto no qual esse trabalho se insere, o que teria provocado também impactos políticos em Freire:

As experiências de Paulo Freire na África remodelaram sua pedagogia. Inserido em processos de reconstrução nacional, realizou a simbiose entre educação e forças produtivas, incorporando o trabalho como princípio educativo. Essa evolução do seu

\footnotetext{
${ }^{8}$ Para um resumo conciso e consistente da trajetória freiriana e de suas distintas "fases", cf. Tagliavia (2008, p. 16-43).
} 
Ensino, Saúde e Ambiente - v. 14 n. esp. (2021): Dossiê Paulo Freire para além dos 100 anos: construir utopias, transformar a realidade, p. 245-268.

Lutas Sociais e Educação Popular

pensamento, ele deve ao seu encontro com a África; os aprendizados aí construídos foram muito importantes nas obras escritas posteriormente. Paulo Freire radicalizou aí seu pensamento. Sua pedagogia continuou humanista, mas agora entendendo melhor, na prática, como o sistema econômico era desumanizador (GADOTTI, 2011, p. 8-9)

Em Por uma pedagogia da pergunta, um dos livros "dialogados" de Freire, produzido a partir de uma conversa com seu parceiro Antonio Faundez, em 1984, podemos localizar a pertinência dos argumentos de Gadotti. A perspectiva política revolucionária anticolonial já presente na Pedagogia do oprimido - reforçada pelas experiências africana e outras, como o contato com os revolucionários sandinistas na Nicarágua - alia-se a críticas aos próprios limites de algumas dessas experiências, que não conseguem superar a lógica colonial internamente, gerando elites dirigentes que acabam por se afastar de seus povos (FREIRE, 2011c, p. 127-131).

Freire identifica nesses processos o caráter de classe desses fenômenos, que se manifestam tanto na sociedade quanto na educação. Por sua incapacidade de superar a própria condição de classe pequeno-burguesa, integrando-se ao povo trabalhador para apreender suas necessidades - Freire utiliza o termo "suicídio de classe", do líder revolucionário caboverdiano Amílcar Cabral -, os grupos dirigentes afastam-se dessas necessidades, reproduzindo uma nova condição colonial, impondo sua ideologia e sua cultura ao povo, como se fossem representativas do "interesse nacional" (FREIRE, 2011c, p. 128-129).

O educador pernambucano reconhece as complexidades dos processos pós-coloniais e aposta no papel de uma educação renovada como um "estímulo ao aprofundamento necessário da mudança da sociedade". Para tal, é necessário convocar o povo para participar da construção da escola, o que significa tornar a educação uma ferramenta não apenas de produção e difusão de saber, mas uma construtora da própria identidade cultural popular, em nível local e nacional: “as classes populares no poder não apenas precisam ser atendidas na demanda de educação de seus filhos e filhas, mas precisam também participar ativamente, da sua reinvenção, ao lado dos educadores profissionais" (FREIRE, 2011c, p. 135).

As considerações de Paulo Freire acerca dos limites das experiências revolucionárias e do encaminhamento de possíveis respostas sinalizam que a superação da condição colonial é resultante de um processo de construção, que precisa convocar as classes populares a participar dos processos políticos - para contrarrestar a tendência ao distanciamento entre governantes e governados - e dos processos educativos, visando a construção de uma efetiva comunidade escolar, que seja uma espaço de produção e difusão de conhecimentos 
Ensino, Saúde e Ambiente - v. 14 n. esp. (2021): Dossiê Paulo Freire para além dos 100 anos: construir utopias, transformar a realidade, p. 245-268.

\section{Lutas Sociais e Educação Popular}

emancipatórios e de construção de identidades culturais, que, sem abandonar as tradições, estejam abertas ao novo e ao diverso.

Foi precisamente isso que Paulo Freire procurou levar para a escola pública paulistana, aos sessenta e sete anos de idade, quando assumiu o posto de Secretário de Educação da Prefeitura Municipal de São Paulo, que ocupou entre 1989 e 1991, quando decidiu se demitir, para, aos setenta anos de idade, se dedicar aos estudos e à escrita. ${ }^{9}$ Publicou sete livros entre 1991 e 1996, antes da sua morte, em 02 de maio de 1997, mudando a forma de seus livros “dialogados", característicos de sua produção da década de 1980, para textos mais "autorais" que refletiam acerca da formação e do trabalho docente e sobre a sua atuação como gestor (TAGLIAVIA, 2008, p. 40-43).

A obra da década de 1990 amplia as preocupações de Freire em direção a questões que se tornaram mais prementes a partir desse período, que vê crescer o interesse pelas relações (e opressões) de gênero e interraciais, pelo multiculturalismo, pela questão da formação das identidades, da alteridade, das "diferenças" e outros elementos que constituem o que se poderia classificar, genericamente, como campo da "cultura". Por exemplo, em seu último livro publicado em vida, Pedagogia da autonomia, de 1996, Paulo Freire escreve:

[...] uma das tarefas mais importantes da prática educativo-crítica é propiciar as condições em que os educandos, em suas relações uns com os outros e todos com o professor ou a professora, ensaiam a experiência profunda de assumir-se. Assumirse como ser social e histórico, como ser pensante, comunicante, transformador, criador, realizador de sonhos, capaz de ter raiva porque capaz de amar. Assumir-se como sujeito porque capaz de reconhecer-se como objeto. A assunção de nós mesmos não significa a exclusão do outro. É a "outredade" do "não eu", ou do tu, que me faz assumir a radicalidade do meu eu.

A questão da identidade cultural, de que fazem parte a dimensão individual e a de classe dos educandos, cujo respeito é absolutamente fundamental na prática educativa progressista, é problema que não pode ser desprezado. Tem que ver com a assunção de nós por nós mesmos. É isto que o puro treinamento do professor não faz, perdendo-se e perdendo-o na estreita e pragmática visão do processo (FREIRE, 2019, p. 42).

No título desta seção, qualificamos Paulo Freire como um "filósofo da práxis

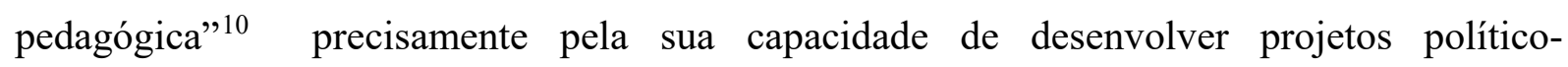

\footnotetext{
${ }^{9}$ Ele também encerra seu ciclo como professor da UNICAMP, posto que ocupou entre 1980 e 1990.

${ }^{10}$ Entendemos aqui filosofia da práxis no sentido que lhe é conferido por Gramsci, principalmente no décimo primeiro de seus Quaderni del cárcere (2007).
} 
Ensino, Saúde e Ambiente - v. 14 n. esp. (2021): Dossiê Paulo Freire para além dos 100 anos: construir utopias, transformar a realidade, p. 245-268.

\section{Lutas Sociais e Educação Popular}

pedagógicos fundamentados em princípios bem definidos - que aqui sintetizamos com uma noção ampla de anticoloniais -, mas, ao mesmo tempo, abertos ao contexto, sem preocupações teóricas sistemáticas, buscando uma reflexão a partir de balanços de experiências pedagógicas anteriores, sem o receio de assumir eventuais equívocos - que, normalmente, não podem ser mesmo previstos, considerando que a relação ensinoaprendizagem ocorre em situações complexas e de dificílima antecipação. E, com uma trajetória rica de experiências como foi a de Paulo Freire, as reflexões que ele legou abrem um universo de possibilidades de exploração teórica, mas, sobretudo, de realização de projetos pedagógicos emancipatórios - o que nos ajuda a compreender sua relevância atual, inclusive em nível internacional.

\section{UM BREVE PANORAMA ACERCA DOS USOS DE PAULO FREIRE PELO MUNDO}

Como dissemos na Introdução, acreditamos que o grande impacto que Paulo Freire continua a exercer ao redor do mundo deve-se às características da sua obra, profundamente imbricada na sua trajetória político-pedagógica, refletindo sobre suas experiências profissionais, e deixando incontáveis possibilidades para se pensar as relações de ensino e aprendizagem. Além do fato, por certo, de Freire ter atuado em várias partes do mundo, principalmente em países ditos "em desenvolvimento", procurando responder de modo prático a problemas práticos, deixando reflexões teóricas abertas, mas relacionadas a questões concretas de realidades sociais consideravelmente distintas, economicamente desiguais e culturalmente diversas.

E é precisamente isso que encontramos na literatura internacional que trabalha com Paulo Freire - e, com isso, não estamos falando de trabalhos "freirianos", necessariamente, como dito na Introdução, mas de autores que incorporam diversas contribuições do educador pernambucanos para abordar distintos problemas. As ideias de Paulo Freire influenciam diversas propostas pedagógicas, de formas muito variadas, mas geralmente voltadas a resoluções de problemas práticos do ensino.

A questão basilar da teoria e da prática pedagógica, a relação entre diretividade e não diretividade do processo de ensino, é abordada por Drew Chambers (2019), em perspectiva filosófica acerca da obra de Paulo Freire. Chambers compara os argumentos de autores que defendem o aspecto mais diretivo, embora não manipulador, da pedagogia freiriana, com outros que defendem sua característica mais dialógica e libertadora. No entendimento do autor, esta seria uma oposição inadequada, na medida em que, em Freire, e de modo geral, na 
Ensino, Saúde e Ambiente - v. 14 n. esp. (2021): Dossiê Paulo Freire para além dos 100 anos: construir utopias, transformar a realidade, p. 245-268.

\section{Lutas Sociais e Educação Popular}

prática pedagógica - e, em particular, no ensino de filosofia, que é a preocupação do autor algum nível de diretividade precisa coincidir com uma pedagogia que vise a emancipação, considerando que o ato educativo não é "puro", nem "perfeito". Para o autor, ser um docente "freiriano" não significa o abandono de aulas expositivas e da diretividade em sala de aula, mas a busca por uma pedagogia que concilie os métodos diretivos com os dialógicos em busca de uma educação "problematizadora" (problem-posing education).

Esse conceito de problem-posing education também é utilizado por Steven Drouin (2018), que, refletindo acerca de sua própria prática e de sua proposta de "Laboratório de democracia", utiliza a noção de educação problematizadora de Freire para trabalhar o tema da participação dos alunos na compreensão e no enfrentamento coletivo de problemas escolares, como questões materiais, violência e racismo. Ele contesta a noção de que a escola seria um espaço restrito à assimilação de conteúdos acadêmicos e habilidades que farão sentido aos estudantes apenas num distante futuro, e identifica na concepção freiriana uma base de sustentação para a nova e crescente realidade educativa que põe o estudante no centro (student-centered) de uma aprendizagem focada na pesquisa (inquiry-focused).

Kuk e Tarlau (2020) abordam a questão da proposta "problematizadora" de Paulo Freire a partir de um balanço bibliográfico a respeito da questão da aprendizagem em movimentos sociais (social movement learning), a partir de estudos sobre educação popular e movimentos sociais. Apesar de sinalizar que, ao menos no que diz respeito à América Latina, a educação popular é bem mais ampla do que a pedagogia freiriana, afirmam que, em decorrência da rápida tradução das obras de Freire para o inglês, sua influência foi transformadora para a educação nos Estados Unidos, impulsionando o repensar das relações entre professores e estudantes nas salas de aula e nos movimentos sociais, e gerando discussões a respeito das articulações entre educação e política, sobre a relação entre os intelectuais e a questão da diretividade pedagógica, e acerca do problema das interseccionalidades das opressões.

Ainda em contexto estadunidense, num momento de acirramento social marcado pela ascensão de grupos de extrema direita, cuja marca é a violência política física e verbal, De Lissovoy e Cook (2020) partem do arcabouço teórico de Freire com o intuito de sustentar sua concepção de diálogo contra as concepções liberais, marcadas por apelos genéricos à "unidade" e à defesa da "liberdade de expressão" que ajudam a mascarar situações de opressão. Contrariamente a esse tipo de "humanismo ingênuo", que parte do suposto de uma identidade abstrata, o diálogo "problematizador" teria o intuito a trazer à tona as diferenças, as assimetrias e os antagonismos que atravessam o espaço escolar e a sala de aula. O diálogo 
Ensino, Saúde e Ambiente - v. 14 n. esp. (2021): Dossiê Paulo Freire para além dos 100 anos: construir utopias, transformar a realidade, p. 245-268.

\section{Lutas Sociais e Educação Popular}

deve abrir espaço à fala dos "estudantes marginalizados", a encontros "desconfortáveis" que visem revelar as (e libertar das) estruturas de opressão, e não promovam a indiferença através de meras "conversas" que normalizam essas estruturas.

A preocupação com a revelação das estruturas de opressão e sua superação também é a questão posta por Muller e Boutte (2019). Os autores partem da compreensão de opressão, tal como compreendida por Paulo Freire, para se contrapor à noção superficial de opressão, entendida como ações as individuais isoladas de racismo, sexismo, classismo e outras, que, portanto, poderiam ser enfrentadas, com abordagens individualizantes. Além das opressões interseccionais, os autores qualificam a culturas de testes de avaliação externa, muito comum nos Estados Unidos, como uma forma de opressão institucional que constrange a ação docente autônoma. Concluem sugerindo que as opressões devem ser "nomeadas" e combatidas com cooperação, unidade, organização coletiva e busca por uma síntese cultural das diversidades.

Os testes padronizados de avaliação externa também são criticados por David Stevens (2010), sobretudo no que diz respeito às noções de qualidade na formação docente, na Inglaterra e no País de Gales. O autor analisa a concepção de docência que fundamenta os testes padronizados de certificação profissional dos professores a partir do que chama de "pedagogia crítica" de Freire, que é utilizada como ferramenta, ao mesmo tempo, de crítica às limitações da perspectiva de formação de professores desses testes, e de anunciação de uma concepção alternativa ao "modelo da competência". O autor realiza uma pesquisa empírica que aponta a limitação da formação docente com base nesse modelo, mas afirma a existência de interesse de professores e alunos de adotar uma perspectiva reflexiva e pautada na problematização das situações de aprendizagem.

Razzak (2020) reflete acerca das contribuições da "pedagogia dialógica" de Paulo Freire para o ensino no Reino do Bahrain. De acordo com a autora, o país vem passando por um processo de reforma educacional coincidente a um projeto nacional de desenvolvimento econômico, diversidade produtiva, geração de empregos e melhoria de vida para a população. Para a autora, a pedagogia freiriana pode ofertar elementos para se pensar um ensino que forme para as "habilidades" necessárias ao "século 21", como pensamento crítico, reflexão, autoconsciência e consciência social, engajamento e aprendizado conduzido pelo estudante, criatividade, senso de pertencimento, confiança, tomada de decisão, resolução de problemas, mobilização prática dos saberes e outras. Apesar de toda a mobilização e das reformas institucionais, Razzak sinaliza para as dificuldades em superar concepções pedagógicas convencionais que geram resultados pouco efetivos, e busca apresentar o arcabouço pedagógico freiriano como caminho possível para o avanço da política educacional em seu país. 
Ensino, Saúde e Ambiente - v. 14 n. esp. (2021): Dossiê Paulo Freire para além dos 100 anos: construir utopias, transformar a realidade, p. 245-268.

\section{Lutas Sociais e Educação Popular}

Com um recorte consideravelmente distinto ao de Razzak, o taiwanês Yi-Huang Shih (2018) ressalta aspectos dos escritos de Freire que representem características a ser desenvolvidas pelos docentes, com o intuito do desenvolvimento de uma relação de ensino e aprendizagem que tenha como fundamento o diálogo: um ensino com base no amor, na humildade, na esperança, no humor, no silêncio, na promoção do pensamento crítico e na crença na melhoria da vida dos alunos. Para tal, é necessário que o ensino garanta a todos o direito à palavra, que conceba um ensino que não se manifeste como o "depósito" de ideias na cabeça de outros e que o diálogo não consiste em argumentos que visem a pura polêmica e a hostilidade.

Suoranta e Tomperi (2021) buscam resgatar o histórico da recepção do pensamento de Paulo Freire na Finlândia, através de uma pesquisa bibliográfica que cobre um período que se inicia no começo da década de 1970 e se encerra na primeira década do século 21, além de realizarem entrevistas com educadores de várias gerações dentro desse período, com o intuito de resgatar memórias de possíveis usos de Paulo Freire em processos pedagógicos. Os autores concluem que a influência do educador pernambucano ocorreu sobretudo no campo da educação de adultos desde a década de 1970, e muito pouco penetrou no pensamento acadêmico finlandês até a década de 2000, quando esse interesse cresceu e se aproximou das reformas educacionais e do cotidiano escolar. Os autores concluem que a perspectiva freiriana contribuiu de forma importante para o encaminhamento das reformas educacionais finlandesas e ainda teria mais a contribuir.

Por fim, Brooks (2018) estuda as possibilidades de um aprendizado emancipatório em "organizações baseadas em comunidade" no México, aproximando a "pedagogia emancipatória crítica" de Paulo Freire do pensamento indígena que fundamenta o movimento zapatista, analisando esse movimento a partir do conceito de ético-onto-epistemologia, de Karen Barad. A autora realiza uma pesquisa em formato de "estudo de caso organizacional" junto a uma organização comunitária, trazendo a contribuição pedagógica de Paulo Freire para refletir acerca do caráter político da educação e sobre a postura ética envolvida na questão do ensino, necessárias a experiências de organização política e educativa que se proponham horizontais.

Como dito na Introdução, nosso intuito com a apresentação dessas recepções do pensamento de Paulo Freire pelo mundo não tiveram o intuito de serem exaustivas, mas de apresentar uma pequena "amostra" dos usos de Freire em contextos socioeconômicos e culturais muito diversos, enquanto, por contraste, no Brasil - país de origem do educador, para o qual ele deu inúmeras contribuições e no qual ele é considerado "patrono da educação" -, a pedagogia freiriana é tratada, por algumas autoridades públicas, com desprezo e 
Ensino, Saúde e Ambiente - v. 14 n. esp. (2021): Dossiê Paulo Freire para além dos 100 anos: construir utopias, transformar a realidade, p. 245-268.

\section{Lutas Sociais e Educação Popular}

desqualificação - chegando a atribuir à pessoa de Freire a responsabilidade pelos supostos "fracassos" da educação nacional. Muitas outras contribuições poderiam ser trazidas, como os usos de Freire para abordar temas como relações étnico-raciais, trabalhos pedagógicos com imigrantes nos países centrais e ecopedagogia, para ficar em alguns exemplos.

\section{CONSIDERAÇÕES FINAIS: O RETROCESSO DE UMA PEDAGOGIA ANTI PAULO FREIRE}

A partir de uma longa experiência como professor dos ensino básico e superior, como consultor e conselheiro sênior no programa de educação da Bill \& Melinda Gates Foundation, de pesquisas de campo em escolas, de inúmeras entrevistas com diversas lideranças do mundo empresarial, político e militar, Tony Wagner (2014) realiza um duro balanço sobre os rumos da política educacional estadunidense, que recentemente adotou uma lógica de avaliações governamentais externas, acreditando que a padronização de conteúdos mínimos e testes de nivelamento dos alunos garantiria uma educação de qualidade para as crianças e jovens dos Estados Unidos.

Contudo, frequentemente, o que ele captou a partir de sua pesquisa foi a percepção, por parte de professores e gestores, de que todo o esforço pedagógico do sistema de ensino estava voltado para a realização daqueles testes padronizados, o que acabava orientando o cotidiano escolar para a preparação para o momento das avaliações. Com isso, se enfraqueceu a autonomia de trabalho dos docentes e se limitou a aprendizagem à memorização dos conteúdos dos testes. Assim, além das dificuldades para o desenvolvimento de relações de ensino-aprendizagem significativas, se foi criando a convicção de que o que se media com os testes eram os aspectos menos relevantes do processo pedagógico.

Sob diversos aspectos, porém, Wagner constata que a relação do estudante com o conhecimento deve ser muito mais ativa do que a simples memorização. Seja do ponto de vista da preparação para a cidadania nas sociedades democráticas, da relação com a informação num momento de uso generalizado de internet, redes sociais e outras mídias que conduzem quantidades incontáveis de dados, nem sempre de boa procedência, e das habilidades necessárias para o ingresso no ensino superior ou para a inserção na lógica produtiva da chamada "economia 4.0", a limitação da escola a uma instituição que se organiza, de modo convencional, para ensinar a memorizar conteúdos, é bastante inadequada à realidade atual. 
Ensino, Saúde e Ambiente - v. 14 n. esp. (2021): Dossiê Paulo Freire para além dos 100 anos: construir utopias, transformar a realidade, p. 245-268.

\section{Lutas Sociais e Educação Popular}

Wagner, então, destaca o que chama de "habilidades de sobrevivência" necessárias aos novos tempos, que ele assim sintetiza: 1) pensamento crítico e resolução de problemas; 2) colaboração através de redes de trabalho e liderança por influência; 3) agilidade e adaptabilidade; 4) iniciativa e empreendedorismo; 5) comunicação oral e escrita eficiente; 6) acesso e análise de informações. Por certo, nem todas essas habilidades destacadas são compatíveis com as preocupações pedagógicas de Freire, mas a sua maioria já estava contemplada pela lógica educativa freiriana desde os círculos de cultura organizados no interior do MCP. Politicamente, Freire era orientado pela transformação ativa do mundo, não pela adaptação a uma realidade em constante mudança. Por outro lado, é de se destacar que a pedagogia freiriana está muito mais conectada com as demandas contemporâneas da educação - inclusive quando se considera a vanguarda capitalista dos países centrais - do que boa parte dos gestores e das propostas atuais da educação brasileira, que muito lembram as falhas iniciativas estadunidenses analisadas por Wagner.

O sentido geral das políticas educacionais no Brasil atual é anti Paulo Freire tanto no seu aspecto político deliberado, ou seja, pela lógica de "guerra cultural" contra o pensamento progressista empreendida pelo governo Bolsonaro (LEHER, 2020), expresso por movimentos como o "Escola sem partido", quanto pelos aspectos tecnicistas, militaristas e de submissão aos interesses do mercado, que podem ser observados na Base Nacional Comum da Formação de Professores da Educação Básica (BNCFP), nas escolas cívico-militares e em propostas como o Future-se. O enfraquecimento da autonomia docente com um projeto de formação de professores voltado para a mera aplicação dos conteúdos da base curricular nacional, a busca pela disciplina estudantil por meio da obediência a uma lógica hierárquica verticalizada e a submissão da educação à lógica de mercado não são apenas anti Paulo Freire. São obstáculos à construção de um país autônomo, moderno, inclusivo e capaz de oferecer condições de vida dignas ao conjunto de sua população.

Por fim, como disse Walter Kohan, mais do que nunca, é urgente a valorização do exemplo, da obra e da práxis do patrono da educação brasileira.

\section{REFERÊNCIAS}

ARY, Z. Uma experiência de educação popular: o Centro de Cultura D. Olegarinha. Trabalho apresentado à Escola de Serviço Social de Pernambuco para obtenção de título de Assistente Social. 1962. Disponível em:

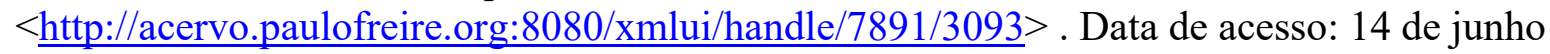
de 2021. 
Ensino, Saúde e Ambiente - v. 14 n. esp. (2021): Dossiê Paulo Freire para além dos 100 anos: construir utopias, transformar a realidade, p. 245-268.

\section{Lutas Sociais e Educação Popular}

BEISIEGEL, C de R. Estado e educação popular: um estudo sobre a educação de adultos em São Paulo. Brasília: Líber Livro, 2004.

BROOKS, A K. Agential Realism in a Community-Based Organization in Mexico: An Ethico-Onto-Epistemology of Emancipatory Learning. Adult Education Quarterly, v. 69, n. 1, p. 1-18, 2018. Disponível em:

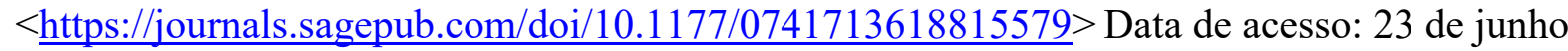
de 2021.

CHABALGOITY, D. Cristianismo conservador e ataques a Paulo Freire: apontamentos para um debate necessário. In: REBUÁ, Eduardo; COSTA, Reginaldo S.; GOMES, Rodrigo Lima R.; CHABALGOITY, Diego (orgs.). (Neo)fascismos e Educação: reflexões críticas sobre o avanço conservador no Brasil. Rio de Janeiro: Mórula Editorial, 2020.

CHAMBERS, D W. Is Freire Incoherent? Reconciling directiveness and dialogue in Freirean Pedagogy. Journal of Philosophy of Education, Vol. 00, No. 0, 2019, p. 1-26. Disponível em: $<$ https://onlinelibrary.wiley.com/doi/10.1111/1467-9752.12340 $>$. Data de acesso: 03 de maio de 2021.

COELHO, G. MCP. História do Movimento de Cultura Popular. Recife: Ed. do autor, 2012.

COELHO, G. Paulo Freire e o Movimento de Cultura Popular. In: ROSAS, Paulo (org.). Paulo Freire: educação e transformação social. Recife: EdUFPE, 2002, p. 31-95.

DE LISSOVOY, N; COOK, C B. Active words in dangerous times: Beyond liberal models of dialogue in politics and pedagogy. Curriculum Inquiry, v. 50, n. 1, p. 78-97, 2020.

Disponível

em: $<$ https://www.tandfonline.com/action/showCitFormats?doi=10.1080\%2F03626784.2020. 1735922>. Data de acesso: 23 de junho de 2021.

DROUIN, S D. Laboratories of democracy: utilizing problem-posing education in our classrooms. Multicultural Education, v. 26, no 1, p. 31-34, Fall 2018. Disponível em

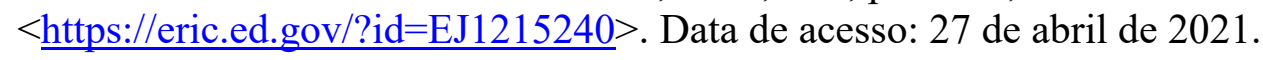

FERNANDES, C; TERRA, A. 40 horas de esperança. O método Paulo Freire: política e pedagogia na experiência de Angicos. São Paulo: Ática, 1994.

FREIRE, P. A África ensinando a gente. Angola, Guiné-Bissau, São Tomé e Príncipe. 2a ed. São Paulo: Paz e terra, 2011b.

FREIRE, P. Cartas à Guiné-Bissau. Registros de uma experiência em processo. $5^{\mathrm{a}}$ ed. São Paulo: Paz e terra, 2011a.

FREIRE, P. Conscientização e alfabetização: uma nova visão do processo. In: FÁVERO, Osmar. Cultura popular e educação popular: memória dos anos 60. Rio de Janeiro: Graal, 1983.

FREIRE, P. Educação como prática da liberdade. $21^{\text {a }}$ ed. São Paulo: Paz e terra, 1992. 
Ensino, Saúde e Ambiente - v. 14 n. esp. (2021): Dossiê Paulo Freire para além dos 100 anos: construir utopias, transformar a realidade, p. 245-268.

Lutas Sociais e Educação Popular

FREIRE, P. Pedagogia da autonomia. Saberes necessários à prática educativa. $59^{\mathrm{a}}$ ed. Rio de Janeiro/São Paulo: Paz e terra, 2019.

FREIRE, P. Pedagogia do oprimido. 49ª Reimpressão. São Paulo: Paz e terra, 2005.

FREIRE, P; FAUNDEZ, A. Por uma pedagogia da pergunta. $7^{\text {a }}$ ed. São Paulo: Paz e terra, $2011 \mathrm{c}$.

FREIRE, P. Primeiro livro: "revi tudo". Em Aberto, Brasília, v. 26, n. 90, p. 175-178, jul./dez. 2013. Disponível em:

<http://www.emaberto.inep.gov.br/ojs3/index.php/emaberto/article/view/2757>. Data de acesso: 17 de abril de 2021.

FREIRE, P et al. Relatório final do Seminário Regional de Educação de Adultos, preparatório ao II Congresso Nacional de Educação de Adultos - Pernambuco [1958]. Em Aberto, Brasília, v. 26, n. 90, p. 145-156, jul./dez. 2013. Disponível em:

$<$ http://www.emaberto.inep.gov.br/ojs3/index.php/emaberto/article/view/2750/2488>. Data de acesso: 17 de abril de 2021.

GADOTTI, M. Apresentação: para descolonizar nossas mentes. In: FREIRE, Paulo; FAUNDEZ, Antonio. Por uma pedagogia da pergunta. $7^{\mathrm{a}}$ ed. São Paulo: Paz e terra, 2011.

GADOTTI, M et al. Paulo Freire: uma biobibliografia. São Paulo: Cortez/Instituto Paulo Freire, 1996.

GOMES, R L R. A trajetória inicial de Paulo Freire: do desenvolvimento e das tensões do seu Método de Alfabetização de Adultos (1958-1967). Movimento - Revista de Educação, Niterói, v. 4, n. 7, p. 33-63, jul./dez. 2017. Disponível em:

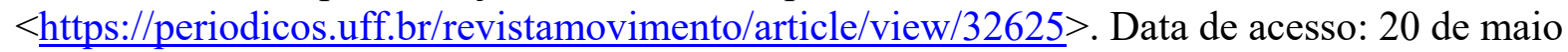
de 2021.

GOMES, R L R. Sentidos da educação popular na história brasileira. Movimento - Revista de Educação, Niterói, v. 7, n. 12, p. 30-53, jan./jun. 2020. Disponível em:

$<$ https://periodicos.uff.br/revistamovimento/article/view/34733 $>$. Data de acesso: 20 de maio de 2021.

GRAMSCI, A. Quaderni del Carcere. Volume Terzo. Torino: Einaudi, 2007.

INEP. Mapa do analfabetismo no Brasil. Brasília: MEC, 2003.

KOHAN, W. Paulo Freire, mais do que nunca: uma biografia filosófica. Belo Horizonte: Vestígio, 2019.

KUK, H-Su; TARLAU, Ra. The confluence of popular education and social movement studies into social movement learning: A systematic literature review. International Journal of Lifelong Education, v. 39, n. 5-6, p. 591-604, 2020. Disponível em:

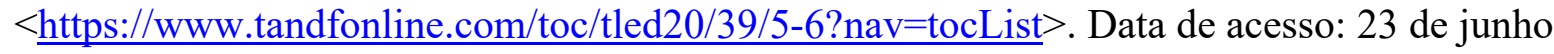
de 2021. 
Ensino, Saúde e Ambiente - v. 14 n. esp. (2021): Dossiê Paulo Freire para além dos 100 anos: construir utopias, transformar a realidade, p. 245-268.

\section{Lutas Sociais e Educação Popular}

LEHER, R. Guerra cultural e Universidade Pública: o Future-se é parte da estratégia de silenciamento. In: GIOLO, Jaime; LEHER, Roberto; SGUISSARDI, Valdemar. Future-se: ataque à autonomia das instituições federais de educação superior e sua sujeição ao mercado. São Carlos, SP: Diagrama Editorial, 2020.

LEMME, P. Educação supletiva. Educação de adultos. In: LEMME, Paschoal. Memórias de um educador. Paschoal Lemme. Volume 5. 2a ed. Brasília: Inep, 2004.

LOURENÇO FILHO, Ml B. O problema da educação de adultos Publicada originalmente na Revista Brasileira de Estudos Pedagógicos, v. 5, n. 14, p. 169-185, ago. 1945]. Revista Brasileira de Estudos Pedagógicos, Brasília, v. 81, n. 197, p. 116-127, jan./abr. 2000. Disponível em: <http://rbep.inep.gov.br/ojs3/index.php/rbep/article/view/1324>. Data de acesso: 23 de maio de 2021.

LYRA, C. As quarenta horas de Angicos: uma experiência pioneira em educação. São Paulo: Cortez, 1996.

MULLER, M; BOUTTE, G S. A framework for helping teachers interrupt oppression in their classrooms. Journal for Multicultural Education, v. 13, n. 1, p. 94-105, 2019. Disponível em: $<$ https://www.emerald.com/insight/content/doi/10.1108/JME-09-2017-0052/full/html $>$. Data de acesso: 21 de junho de 2021.

PAIVA, V. História da educação popular no Brasil: educação popular e educação de adultos. $6^{\text {a }}$ ed. São Paulo: Edições Loyola, 2003.

RAZZAK, N A. Paulo Freire's critical and dialogic pedagogy and its implications for the Bahraini educational context, Educational Philosophy and Theory, v. 52, n. 9, p. 999-1010, 2020. Disponível em:

$<$ https://www.tandfonline.com/doi/full/10.1080/00131857.2020.1716731>. Data de acesso: 09 de junho de 2021.

RODRIGUES, J. O moderno príncipe industrial: o pensamento pedagógico da Confederação Nacional da Indústria. Campinas: Autores Associados, 1998.

SHIH, Yi-Huang. Rethinking Paulo Freire's Dialogic Pedagogy and Its Implications for Teachers' Teaching. Journal of Education and Learning, v. 7, n. 4, p. 230-235, 2018. Disponível em: $<$ https://www.ccsenet.org/journal/index.php/jel/article/view/75420 $>$. Data de acesso: 09 de junho de 2021.

SOARES, L. O educador de jovens e adultos e sua formação. Educação em Revista, n. 47, jun. de 2008, p. 83-100. Disponível em: <

https://www.scielo.br/j/edur/a/br3HrgNWhwfNKhwFmZ3jNkD/?lang=pt $>$. Data de acesso: 07 de junho de 2021.

STEVENS, D. A Freirean critique of the competence model of teacher education, focusing on the standards for qualified teacher status in England. Journal of Education for Teaching, v. 6, 2, 187-196 , p. 2010. Disponível em:

$<$ https://www.tandfonline.com/doi/full/10.1080/02607471003651722>. Data de acesso: $10 \mathrm{de}$ junho de 2021. 
Ensino, Saúde e Ambiente - v. 14 n. esp. (2021): Dossiê Paulo Freire para além dos 100 anos: construir utopias, transformar a realidade, p. 245-268.

Lutas Sociais e Educação Popular

SUORANTA, J; TOMPERI, T. Is There a Nordic Freire? The Reception History of Freirian Ideas in Finland. Journal for Critical Education Policy Studies, v. 19, n. 1 p. 62-97, maio,

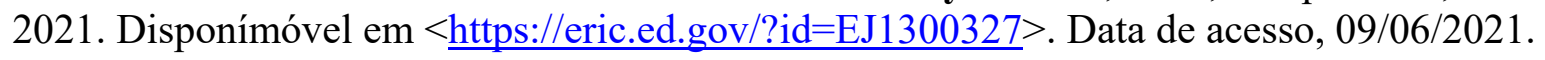

UNESCO. Asistencia técnica para el desarrollo económico. Lake Success, NY: Nações Unidas, 1949.

WAGNER, T. The global achievement gap: why even our best schools don't teach the new survival skills our children need - and what we can do about it.

Philadelphia/PA/USA: Basic Books, 2014.

\section{SOBRE O AUTOR}

\section{RODRIGO LIMA RIBEIRO GOMES}

Professor Adjunto do Instituto de Educação de Angra dos Reis, da Universidade Federal Fluminense (IEAR-UFF). Doutor e Mestre em Educação pela Universidade Federal Fluminense (2009 e 2014) e Graduado em História pela mesma universidade. Foi professor de História da Rede Pública Municipal de Ensino do Rio de Janeiro. 